\title{
Identification, quantification and comparative assessment of costunolide in wild, cultivated and in vitro callus culture of Saussurea lappa by HPLC technique
}

\author{
Zaib-Un-Nisa ${ }^{1 *}$, Safdar Hussain Shah ${ }^{2}$, Ghulam Farooq ${ }^{3}$, Muhammad \\ Anwar Sajad ${ }^{1}$ and Muhammad Anwar Saleem Khan ${ }^{4}$ \\ 1. Department of Botany, Islamia College (A Public Sector University) Peshawar, Peshawar-Pakistan \\ 2. Institute of Biotechnology and Genetic Engineering, Agriculture University, Peshawar-Pakistan \\ 3. Department of Genetics, Hazara University, Mansehra-Pakistan \\ 4. Department of Zoology, University of Swabi, Khyber Pakhtunkhwa Pakistan \\ *Corresponding author's email:zaib2864@gmail.com \\ Citation \\ Zaib-Un-Nisa, Safdar Hussain Shah, Ghulam Farooq, Muhammad Anwar Sajad and Muhammad Anwar Saleem \\ Khan. Identification, quantification and comparative assessment of costunolide in wild, cultivated and in vitro \\ callus culture of Saussurea lappa by HPLC technique. Pure and Applied Biology. Vol. 8, Issue 1, pp910-919. \\ http://dx.doi.org/10.19045/bspab.2019.80033
}

\begin{tabular}{llll}
\hline \hline Received: 11/12/2018 & Revised: 25/02/2019 & Accepted: 04/03/2019 & Online First: 16/03/2019 \\
\hline \hline
\end{tabular}

\section{Abstract}

Saussurea lappa is an endangered medicinal plant. Serious efforts are needed to conserve it by rapid in vitro technique. Plant tissue culture is one of the best way for its conservation. Its root contains a bioactive compound, costunolide which possess anti-carcinogenic, anti-ulcer, antimicrobial and anti-inflammatory etc properties. A simple high performance liquid chromatographic (HPLC) method for identification and quantification of costunulide was established. Shoot and root derived calli were harvested after seven and fifteen days. The ethanolic extracts of calli, cultivated and wild plant roots, petiole and lamina were used. Standard compound, Costunolide and plant materials were extracted into $70 \%$ ethanol and separated on a Perkin Elmer, 200 series using reverse phase column C18 $(25 \mathrm{~cm} \times 4.6 \mathrm{~mm}, 5$ $\mu \mathrm{m})$ with UV visible detector at $225 \mathrm{~nm}$. The mobile phase was HPLC grade methanol and water $(70: 30 \mathrm{v} / \mathrm{v})$ at flow rate of $1 \mathrm{ml} \mathrm{minute}^{-1}$. The total analysis time per sample was set 20 minutes. The establish method showed a good linerity $\left(\mathrm{R}^{2}=0.988\right)$. Costunolide was identified only in roots and root derived calli extracts. Wild root (root c) produced high quantity 1.257 $\mu \mathrm{gml}^{-1}$ of Costunolide followed by fifteen days old (callus b) callus $1.119 \mu \mathrm{gml}^{-1}$ and seven days old callus $1.118 \mu \mathrm{gml}^{-1}$ (callus c) while the quantity from cultivated root (root b, root a) was $1.105 \mu \mathrm{gml}^{-1}, 1.102 \mu \mathrm{gml}^{-1}$ respectively.

Keywords: Calli; Costunolide; High Performance Liquid Chromatography; Plant Roots

\section{Introduction}

S. lappa C.B. Clarke, belongs to Family Asteraceae (Compositae) and commonly known as costus [1]. It is an endangered long, erect perennial herb and is endemic to the valley of Kashmir as well as western Himalayas between 2500 to $3000 \mathrm{~m}$ above the sea level of Pakistan and India [2]. Its root contain a bioactive compound called costunolide which is used against a lot of 
diseases like headache, pain, arthritis, skin diseases, ulcers, cough, flatulence, asthma, colic, fever, general weakness [3] and diarrhea [4]. It warms the center area while regulating the stomach hormones, dyspepsia, vomiting, tenesmus and dysentery [5] as well as treat migraine [6]. Its detail studies verified its pharmacologic action used to treat cardiovascular disorders as well as its anti-ulcer, anticancer, anti-inflammatory and antimicrobial properties [7]. In addition it regulates the central nervous system [8], immune system [9] and inhibits oxidization along with angiogenesis [10]. Besides it regulates growth of the plants as well as repels insects $[11,12]$ and affects parasites $[13,14]$. It is also reported that costunolide possess anti-carcinogenic [15, 16], antiulcer $[17,18,19]$, antimicrobial and antiinflammatory properties as well as extensively investigated for the protein tyrosine phosphate inhibitory behaviour [20]. The over exploitation of S. lappa root for diverse commercial and medicinal purposes gradually decreases the availability of this plant in wild. The plant is enlisted in Endangered plant Species of Wild Fauna and Flora (CITES) and is one of the 37 endangered Himalayan therapeutic plant [21]. Tissue culture is the most efficient technique that allowed inducing and accumulating the metabolite in a short time and small space independent on seasonal and weather changes then the mother plant did, used to obtain higher amounts of bioactive compound directly from callus without sacrificing the endangered $S$. lappa plants in the wild.

\section{Materials and methods}

\section{Sterilization of the media}

Murashige and Skoog media was dispensed in flasks and then sterilized for 20 minutes by autoclaving at $121{ }^{\circ} \mathrm{C}$. Other equipment like scalpel, spatulas and forceps were also sterilized with media. After autoclaving the whole materials were directly transferred to laminar flow cabinet, where subjected for 20 minutes to ultra violet (UV) radiation. The whole culture was carried out in sterilized and aseptic environment in laminar flow cabinet [22, 23, 24]. The present research work was carried out in Plant Tissue Culture Laboratory, Institute of Biotechnology and Genetic Engineering, Agriculture University Peshawar.

\section{Plant materials}

Micropropagated plant shoot and root were surface sterilized [22, 23] and used to derive callus. The used root derived calli were 7 days and fifteens days old. The wild growing plant collected from Kashmir hills (root c) whereas cultivated plants (root (a), leaves and petiole) were collected from Botanical garden of Pakistan Forest Institute, Peshawar and root (b) from Kozagali, Abbottabad. These plants materials were used for High Performance Liquid Chromatography (HPLC) analysis.

Preparation of extracts for high performance liquid chromatography (HPLC)

The determination of costunolide was carried out at centralized laboratory Physics department, University of Peshawar. S. lappa roots (collected from different regions), petiole, lamina and calli derived from micropropagate plant roots (callus "a", seven days old and callus "b" fifteen days old) were shade dried at room temperature. All materials were ground to powder (20 g each) and subjected to successive extraction using ethanol. These materials were left for a week but were shaken daily. The extracts were filtered through Buchner funnel with Watman number one filter paper. The filtrates were evaporated to dryness under reduce pressure at $40{ }^{\circ} \mathrm{C}$ using rotary evaporator. Ethanol extracts were dried and from each samples 1mg of sample was dissolved in 1 ml HPLC grade methanol, filtered and injected into HPLC machine [24].

\section{Preparation of stock solution and} calibration standards

Costunolide standard (97\% pure) for HPLC was purchased from sigma chemicals (Korea). To make costunolide stock solution, weighed $1.0 \mathrm{mg}$ of 
costunolde was dissolved in $1.0 \mathrm{ml}$ of HPLC grade methanol. Calibration standards were prepared to obtained three concentration levels i.e $10 \mathrm{ppm}, 50 \mathrm{ppm}$ and $100 \mathrm{ppm}$ by diluting the costunolide stock solution (1000 ppm) with HPLC grade methanol. The calibration curve was created by plotting the the ratio of costunolide standard peaks area [24]. The retention time for each sample was developed 20 minutes. The standard concentrations were first injected in HPLC and then run each samples one by one.

\section{High performance liquid}

chromatography (HPLC)

For HPLC analysis Perkin Elmer, 200 series was used comprising UV visible detector at 225 wave length. Chromatographic separation was carried out with $\mathrm{C} 18$ reverse phase column $(25 \mathrm{~cm}$ $\times 4.6 \mathrm{~mm}, 5 \mu \mathrm{m})$. The mobile phase was composed of HPLC grade methanol and water $(70: 30 \mathrm{v} / \mathrm{v})$ at flow rate of $1 \mathrm{ml}$ minute $^{-1}$ and injection volume was $20 \mu \mathrm{l}$ the total analysis time per sample was 20 minutes [24].

\section{Results}

\section{Identification and quantification of costunolide}

\section{High Performance Liquid \\ Chromatography of standard compound}

Data regarding identification analysis of costunolide in standard compound is shown in (Table 1). Three different known concentrations of standard were used which was $10 \mathrm{mg} / \mathrm{ml}, 50 \mathrm{mg} / \mathrm{ml}$ and 100 $\mathrm{mg} / \mathrm{ml}$ and the total flow time was set 20 minutes. Different peaks were found at different retention time but the only high peak was obtained at 14.8 minutes in all three concentrations. This peak indicates the presence of standard costunolide compound. The peaks were observed with different peak areas but at same retention time are shown in (Table 2).

Table 1. Data regarding to HPLC analysis of standard compound with different known concentrations showed different peak, peak area, height area \% and normal percentage at the same retention time

\begin{tabular}{|c|c|c|c|c|c|c|}
\hline $\begin{array}{c}\text { Peak } \\
\text { No. }\end{array}$ & $\begin{array}{c}\text { Sample } \\
\text { name and } \\
\text { conc. }\end{array}$ & $\begin{array}{c}\text { Time } \\
(\mathbf{m i n u t e s})\end{array}$ & $\begin{array}{c}\text { Area } \\
{\left[\begin{array}{c}\text { micro volt } \\
\text { seconds] }\end{array}\right.}\end{array}$ & $\begin{array}{c}\text { Height } \\
\text { micro volt } \\
{[\boldsymbol{\mu V}]}\end{array}$ & Area [\%] & $\begin{array}{c}\text { Norm. } \\
\text { Area } \\
{[\%]}\end{array}$ \\
\hline 20 & $\begin{array}{c}\text { Costunolide } \\
(10 \mathrm{mg} / \mathrm{ml})\end{array}$ & 14.8 & 40665.74 & 1923.47 & 51.79 & 51.79 \\
\hline 13 & $\begin{array}{c}\text { Costunolide } \\
(50 \mathrm{mg} / \mathrm{ml})\end{array}$ & 14.8 & 609618.53 & 14780.98 & 91.87 & 91.87 \\
\hline 23 & $\begin{array}{c}\text { Costunolide } \\
(100 \mathrm{mg} / \mathrm{ml})\end{array}$ & 14.8 & 1665458.24 & 38062.11 & 38061.11 & 95.98 \\
\hline
\end{tabular}

Table 2. Data regarding HPLC analysis of different samples showed different peaks, areas, heights, area \% and normal percentage at same retention time. Callus c (fifteen days old), callus b (seven days old), Root a, Root b (cultivated) and Root c (wild)

\begin{tabular}{|c|c|c|c|c|c|c|}
\hline $\begin{array}{c}\text { Peak } \\
\text { No. }\end{array}$ & $\begin{array}{c}\text { Sample } \\
\text { name }\end{array}$ & $\begin{array}{c}\text { Time } \\
{[\mathbf{m i n}]}\end{array}$ & $\begin{array}{c}\text { Area }[\boldsymbol{\mu V} \\
\mathbf{s e c}]\end{array}$ & $\begin{array}{c}\text { Height } \\
{[\boldsymbol{\mu} \mathbf{V}]}\end{array}$ & $\begin{array}{c}\text { Area } \\
{[\%]}\end{array}$ & Norm. Area [\%] \\
\hline 11 & Callus c & 14.8 & 562.85 & 33.63 & 0.00 & 0.00 \\
\hline 17 & Callus b & 14.8 & 587.58 & 38.45 & 0.05 & 0.05 \\
\hline 15 & Root a & 14.8 & 287.15 & 30.73 & 0.00 & 0.00 \\
\hline 14 & Root b & 14.8 & 326.34 & 34.14 & 0.06 & 0.06 \\
\hline 13 & Root c & 14.8 & 1090.86 & 65.97 & 0.02 & 0.02 \\
\hline
\end{tabular}

Three different peak areas of costunolide and their concentrations In (Figure 1) the series 1 shows the chromatogram of the standard compound at concentration of $100 \mathrm{mg} / \mathrm{ml}$. The high peak areas at $2.1,2.2,2.5,3.4,4.4,6.2,14.8$ and 19.8 minutes were observed 3722.9, 4247.5, 4342.6, 29515.5, 2668.1, 19276.6, 
1665458.2 and $3513.6 \mu$ Vsec respectively. The (Figure 1) shows that highest peak area, $1665458.2 \mu \mathrm{V}$ was observed at 14.8 minute. Series 2 indicates the chromatograme of the same standard compound but with $50 \mathrm{mg} / \mathrm{ml}$ concentration. The high peak areas at 2.0, $2.1,2.3,3.1,3.4,4.4,6.2,14.8$ and 19.8 minute were found 6995.8, 11902.6, 4399.3, 1124.9, 13744.3, 4539.1, 8709.0, 609618.5 and $1017.4 \mu$ Vsec respectively. The maximum peak area 609618.5 was observed at retention time 14.8 minute. Series 3 shows the chromatogram of the standard compound with $10 \mathrm{mg} / \mathrm{ml}$ concentration. The peak areas at 10.061, $14.843,16.657,17.694,17.694$ and 19.580 minutes were recorded 46.36, 40665.74, $22.29,16.09$ and $1.40 \mu \mathrm{Vsec}$ respectively. The highest peak area was $40665.74 \mu \mathrm{Vsec}$ among these peak areas recorded at 14.8 minute. All the three concentrations showed peaks on the same retention time and were taken as standard peaks areas to calculate the unknown concentrations of the tested samples.

\section{Calibration curve for different concentrations of costunolide}

ln order to observe the unknown concentrations of the calli and root samples calibration curve for costunolide was obtained under optimum condition by plotting costunolide peaks areas verses its three different concentrations $(10,50$ and $100 \mathrm{mg} / \mathrm{ml}$ ) as shown in (Figure 2). The calibration curve showed good linearity in relatively wide concentration range. The regression equation used for standards was $y=18179 x-19762\left(R^{2}=0.988\right)$.

Data regarded quantitative analysis of costunolide through HPLC is presented in (Table 2) showing different peaks at different time for each samples but costunolide showed the same retention time. Root collected from Kashmir forest ( root c) covered high area is $1090.86 \mu \mathrm{Vsec}$ and also large height $65.97 \mu \mathrm{V}$ of the peak followed by fifteen days old root callus (callus b) $587.58 \mu \mathrm{V} \mathrm{sec}$ and $38.45 \mu \mathrm{V}$ sec and seven days old root callus (callus c)
$562.85 \mu \mathrm{V}$ sec and $33.63 \mu \mathrm{V}$ while root collected from Koza gali, Abbottabad (Root b) showed $326.34 \mu \mathrm{V}$ sec area and 34.14 $\mu \mathrm{V}$ height of the peak. However, the root collected from Pakistan Forest Institute Peshawar (root a) showed less peak area 287.15 and height 30.73 compared to all other samples.

Shoot callus (callus 'a'), lamina and petiole excised from natural plant, extracts were also prepared properly and run through HPLC. Many unknown peaks were found at different time but no peak was observed at 14.8 minute to determine costunolide. The peak area of each sample was used to quantify costunolide in each sample and presented with its chromatographs.

\section{HPLC chromatogram of ethanol extract callus " $b$ "}

The chromatogram of the ethanolic extract of callus ' $b$ ' is shown in (Figure 3 ) with the time shown in minutes. It is clear from the (Figure 3) that at 14.2, 14.8, 17.8 and 17.9 minutes the peaks areas 43.7, 587.5, 34.5 and $26.8 \mu \mathrm{V}$ sec were found respectively. The peak area $587.58 \mu \mathrm{V}$ sec of costunolide was observed at 14.8 minute with the calculated concentration of $1.119 \mu \mathrm{g} / \mathrm{ml}$.

HPLC chromatogram of ethanol extract callus "c"

The chromatogram of the ethanolic extract of callus ' $c$ ' is shown in (Figure 4). It is evident from the (Figure 4) that at 14.6, 14.8 and 17.641 minutes the peaks areas were found 26.43, 562.85 and 983.02 $\mu \mathrm{Vsec}$ respectively. The costunolide peak area $587.58 \mu \mathrm{Vsec}$ at retention time 14.8 minute was observed as shown in (Figure 4). In callus ' $c$ ' the concentration of costunolide was recorded $1.118 \mu \mathrm{g} / \mathrm{ml}$.

\section{HPLC chromatogram of ethanol extract} of root "a"

The chromatogram of the ethanolic extract of root ' $a$ ' is presented in (Figure 5). It is obvious from the (Figure 5) that at retention time 14.3 and 14.8 minutes the peaks areas were recorded 97.51 and $287.15 \mu \mathrm{Vsec}$ respectively. While no peak was appeared on 15 and 16 minutes as 
cleared from the (Figure 5). The costunolide concentration was observed about $1.1028 \mu \mathrm{g} / \mathrm{ml}$.

HPLC chromatogram of ethanol extract of root "b"

The chromatogram of the ethanolic extract of root ' $b$ ' is shown in (Figure 6). It is clear from the (Figure 6) that at retention time 14.8 minute the peak area found was 326.34 $\mu$ Vsec. However, no other peak was observed at 14, 15 and 16 minutes. In root ' $b$ ' the concentration of costunolide was about $1.105 \mu \mathrm{g} / \mathrm{ml}$.
HPLC chromatogram of ethanol extract of root "c"

The chromatogram of the ethanolic extract of root ' $c$ ' is shown in (Figure 7). It is observed from the (Figure 7) that at retention time 14.8 minute the costunolide peak area was appeared $1090 \mu \mathrm{Vsec}$. While no peak was observed on 15 to 16 minutes as clear from (Figure 7). In root 'c' the concentration of costunolide was about $1.257 \mu \mathrm{g} / \mathrm{ml}$. Non significant results were observed in all the tested samples.

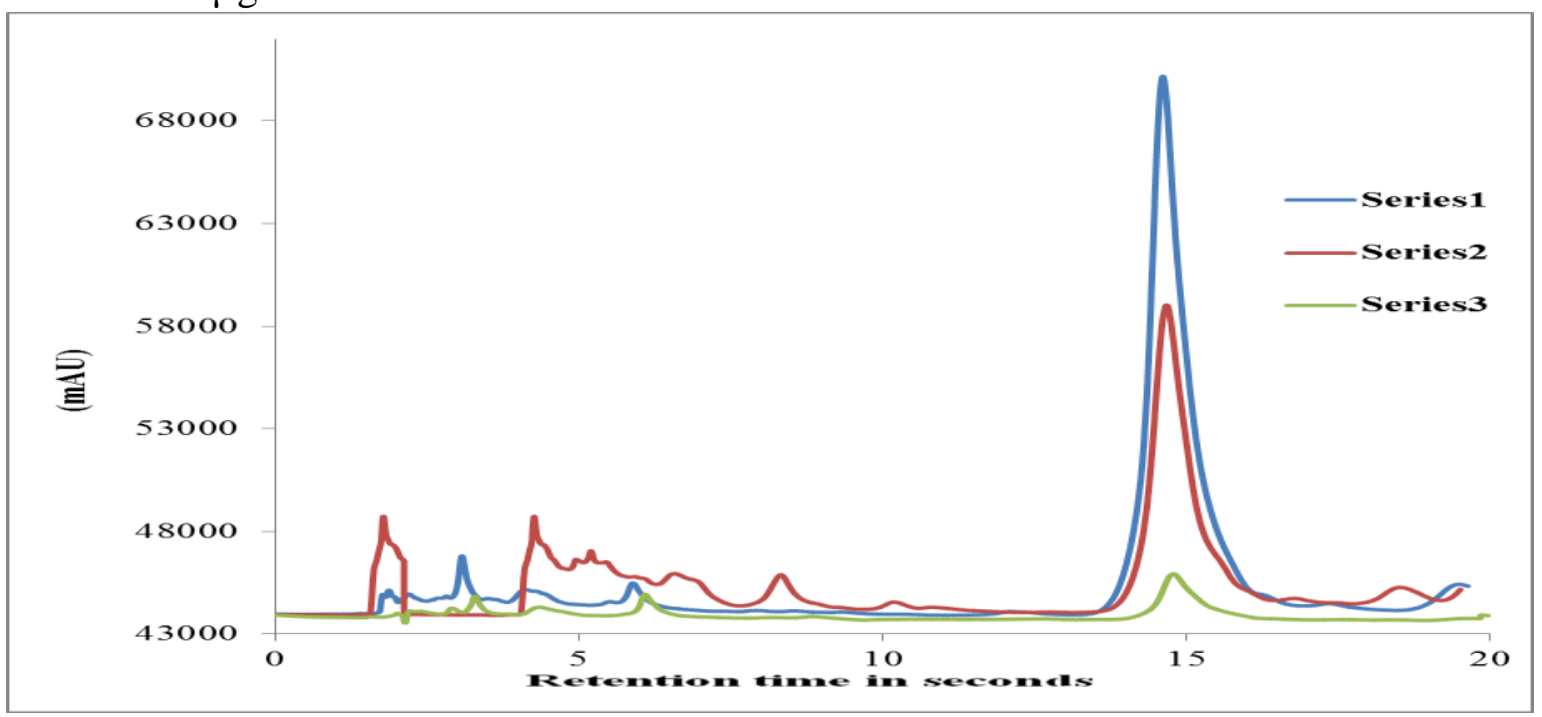

Figure 1. Three different peaks of Costusnolide and its concentrations

Series 1: The chromatogram of Costunolide $100 \mathrm{mg} / \mathrm{ml}$ concentration

Series-2: The chromatogram of Costunolide $50 \mathrm{mg} / \mathrm{ml}$ concentration

Series-3: The chromatogram of Costunolide $10 \mathrm{mg} / \mathrm{ml}$ concentration

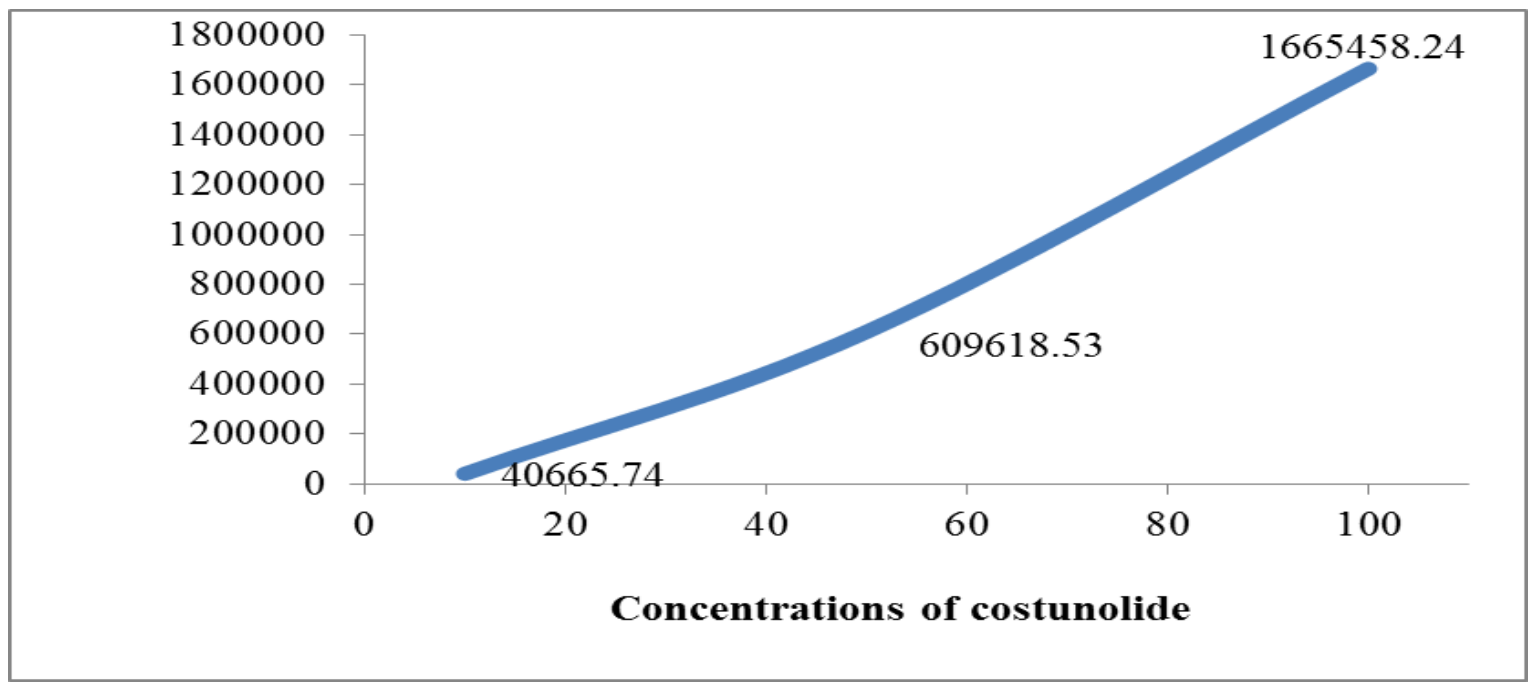

Figure 2. Calibration curve plotted for three different concentrations of costunolide High Performance Liquid Chromatography analysis of root calli and root samples 


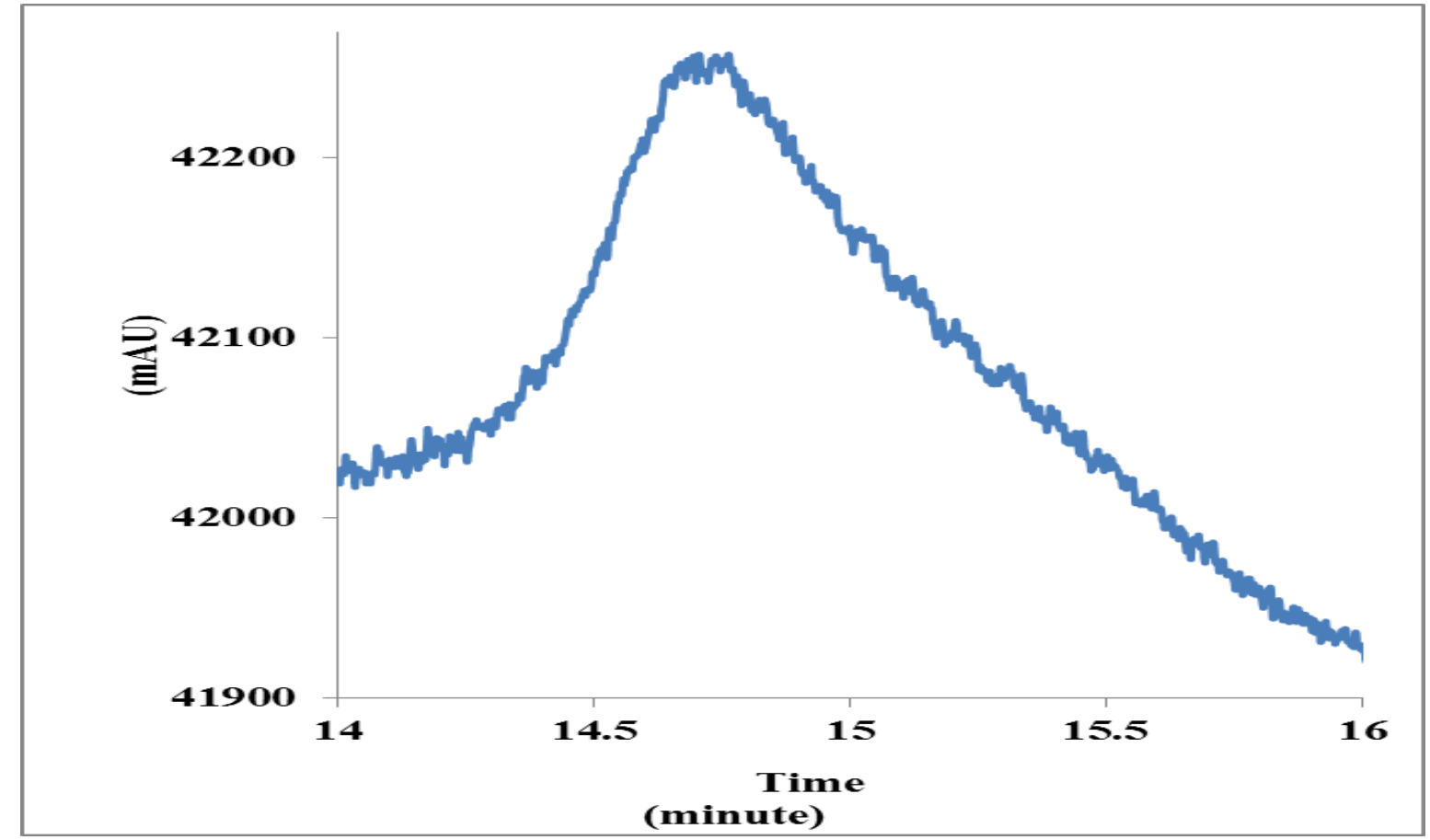

Figure 3. HPLC chromatogram of ethanol extract callus "b"

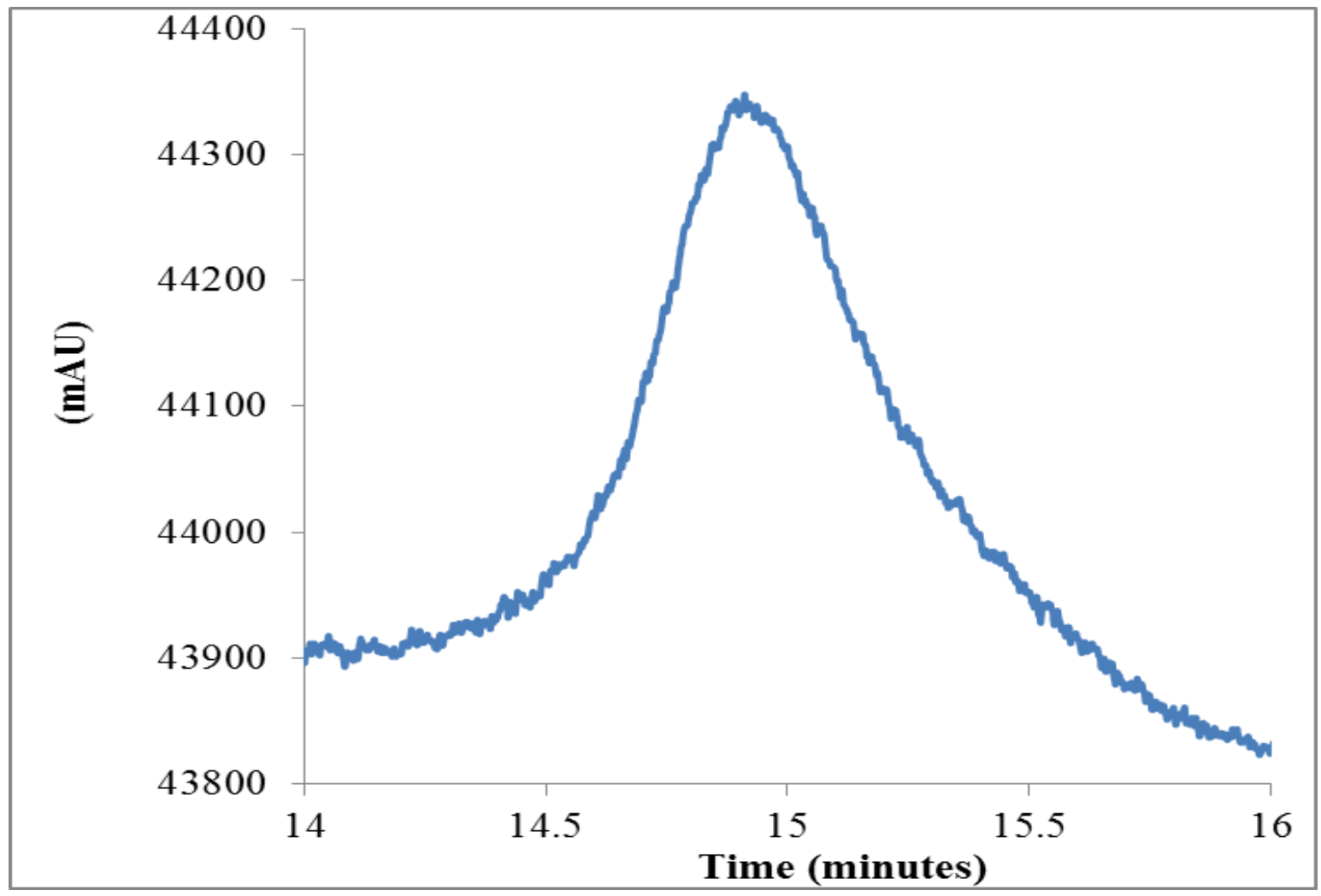

Figure 4. HPLC chromatogram of ethanol extract of callus "c" 


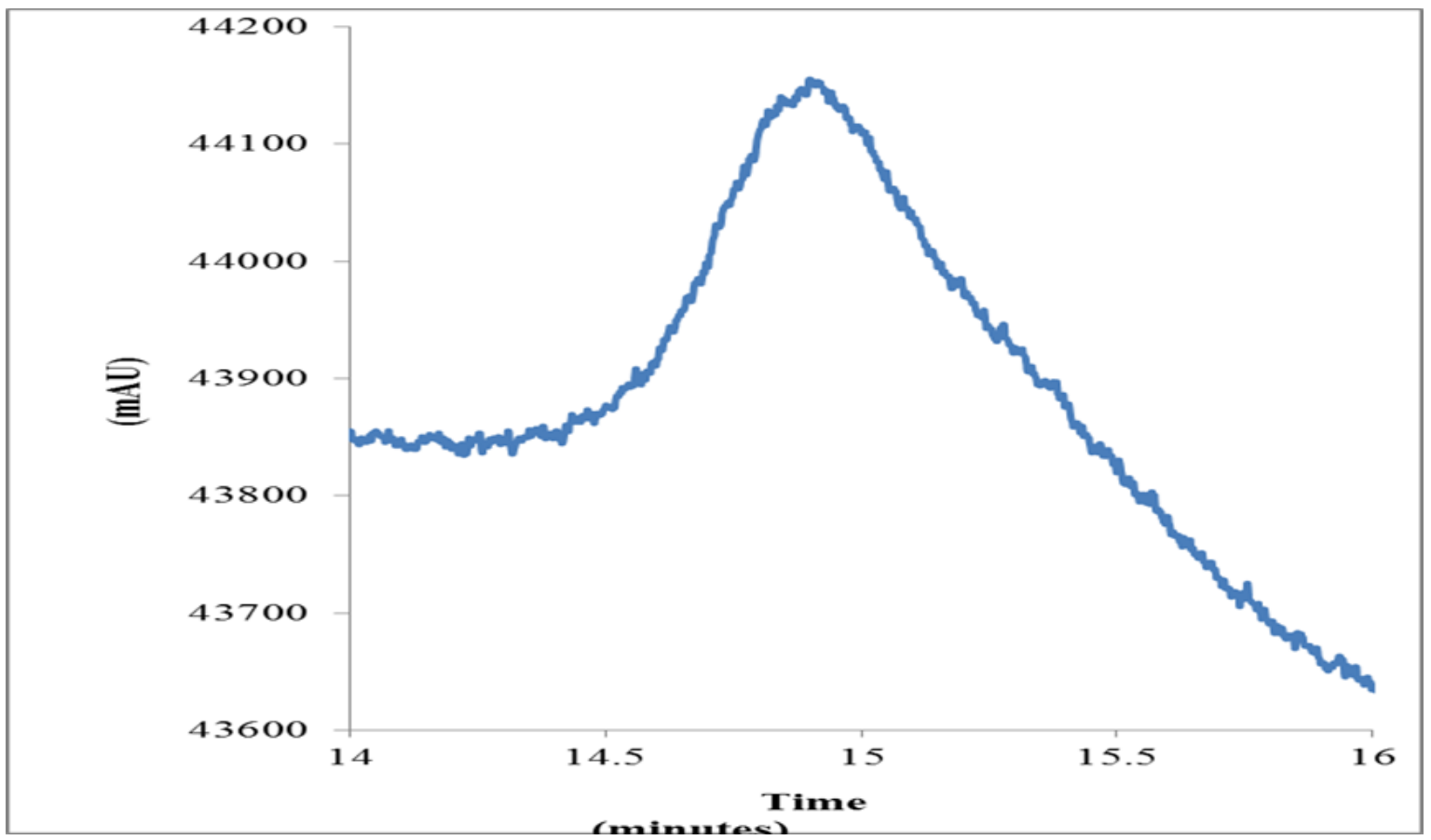

Figure 5. HPLC chromatogram of ethanol extract of root "a"

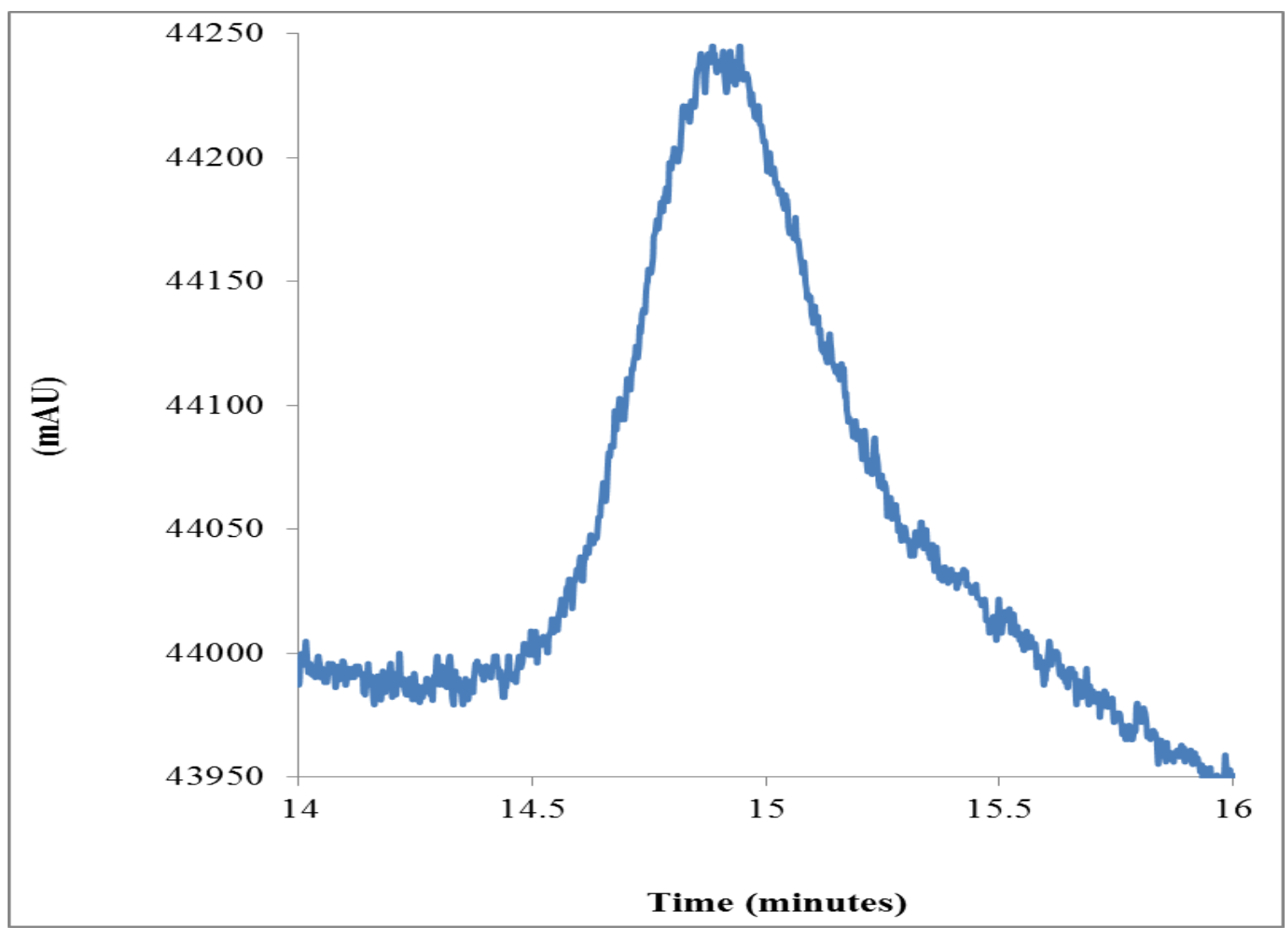

Figure 6. HPLC chromatogram of ethanol extract of root " $b$ " 


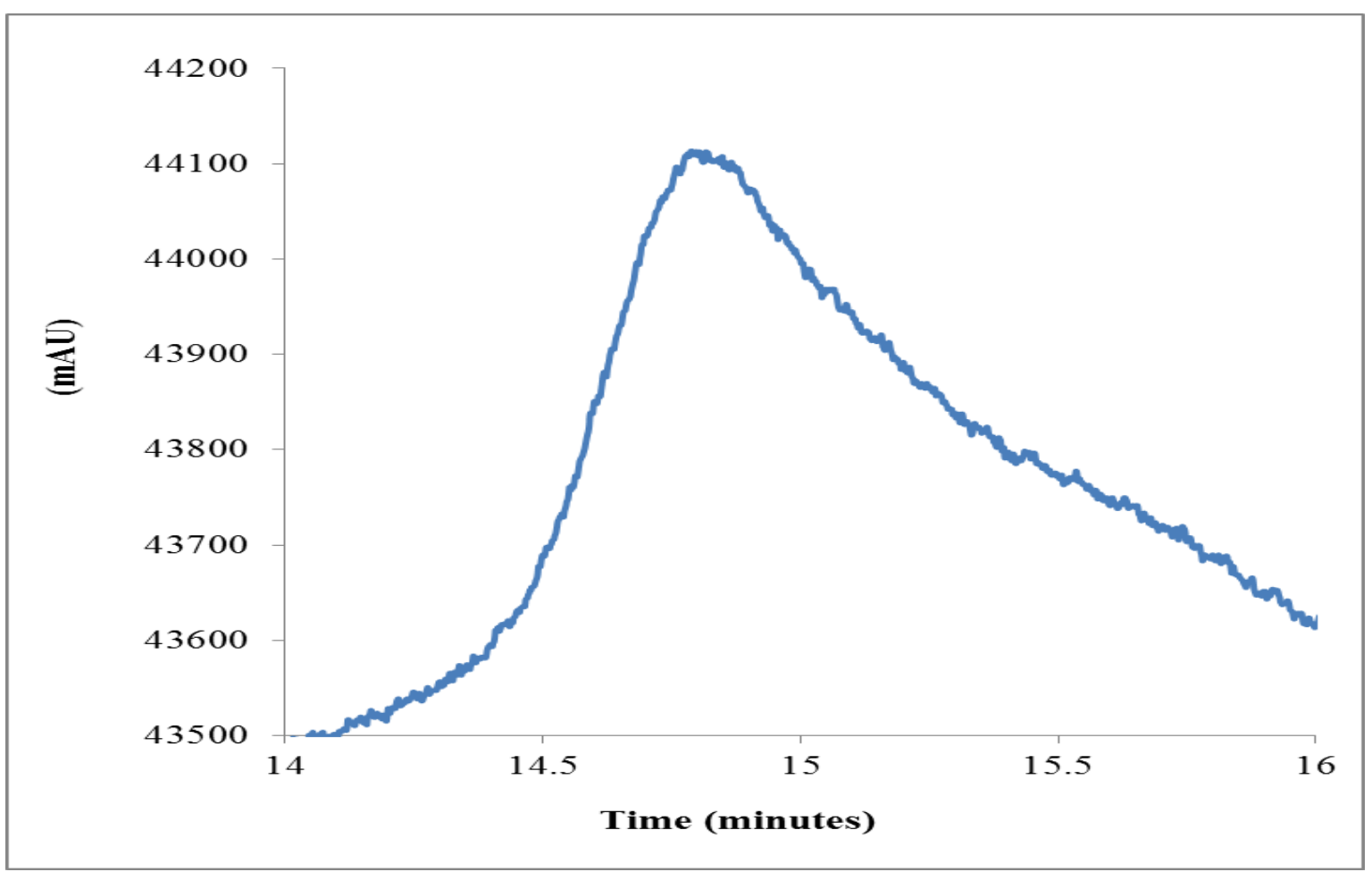

Figure 7. HPLC chromatogram of ethanol extract of root "c"

\section{Discussion}

\section{High performance liquid} chromatographic analysis

HPLC technique was employed to investigate, identify and quantify the quantity of costunolide in calli (root, petiole and lamina), wild and field grown plant's roots, petiole, lamina of S. lappa and compared them with each other. We developed an easy, a cheap and accurate method of HPLC for costunolide quantification in S. lappa. Calli cultures established from seedling and different parts of micropropagated plantlet of $S$. lappa are thought to be an important source of secondary metabolites for such studies. As naturally growing plants have been extensively exploited for medicinal and economic purposes and huge numbers of these plants have been used in folk medicines. In this case, plant tissue culture is the most efficient technique used to obtain higher amounts of bioactive compound, that allowed inducing and accumulating the metabolite in a short time than mother plant did. Our results show that $100 \mathrm{mg} / \mathrm{ml}$ costunolide has many small peaks and a single large peak was observed in 20 minutes on 14.8 seconds so the flow rate was fixed at 20 minutes. In all three concentrations many different peaks were observed but a highest peak was found at the same retention time of 14.8 seconds which identified the presence of the same bioactive compound. The other peaks may be some contamination of the solvent or extracts as these were not found in all the three series or the impurities of the compound as the standard costunolide was 97\% pure. In all ethanolic extracts of natural plant petiole, lamina and callus ' $a$ ' (shoot derived callus) costunolide was not observed while in all samples of roots and root calli costunolide was observed which indicated that it is found only in roots of $S$. Lappa. Our results match with previous reports $[24,25]$. The quantitative HPLC analysis indicated that $S$. lappa root calli cultures give slightly better results than root ' $a$ ' and root ' $b$ '. Furthermore, our report showed that age of calli also affect the concentration of Costunolide as ffiteen days old callus (callus b) produced a bite more amount of the compound compared to 
seven days old callus (callus c). In this case, it is observed that plant tissue culture is the most efficient technique used to obtain higher amounts of bioactive compound, that allowed inducing and accumulating the metabolite in a short time than mother plant did. These conclusions are in agreement with the report of Lima et al. [26]. In between root ' $a$ ' and root ' $b$ ' very little difference in content of costunolid was observed as both roots were collected from cultivated farms of different regions. However, Root 'c' (wild root) showed higher content of Costunolide than callus ' $a$ ', callus ' $b$ ', root ' $a$ ' and root ' $b$ '(cultivated roots). These differences in concentration can be attributed to several environmental and different geographical variations. These results also match the previous reports $[24,25,27,28]$. Plant material (calli) through plant tissue culture technique is free from environmental variations, therefore, it enhance the reproducibility of the experiments and products as well.

\section{Conclusion}

Based on the current research work it is concluded that quantitative HPLC analysis indicated that root callus culture produced the same costunolide bioactive compound and also approximately in similar amount found in the roots of intact cultivated and wild growing plant.

\section{Authors' contributions}

Conceived and designed the experiments: ZU Nisa, Performed the experiments: ZU Nisa, Analyzed the data: G Farooq, Contributed materials/ analysis/ tools: SH Shah, Wrote the paper: MA Sajad \& MAS Khan.

\section{Acknowledgement}

The authors would like to express their appreciation to the chairman, Institute of Biotechnology and Genetic Engineering, Agriculture university, Peshawar and Islamia College, University, Peshawar for providing Laboratory facility. Also very thankful to Centralized Laboratory Physics Department, University of Peshawar for providing Laboratory facility.

\section{References}

1. Kirtikar KR \& Basu BD (2001). Indian Medicinal Plants. Oriental Enterprises 6(2): 1961-1965.

2. Gupta OP, \& Ray GBJ (1967). Pharmacological investigations on Saussurea lappa (Clarke). Indian J Med Res 55: 10.

3. Arora R, \& Bhojwani SS (1989). In vitro propagation and low temperature storage Sassurea lappa C. B. Clarke - an endangered medicinal plant. Plant Cell Rep 8: 44-47.

4. Negi JS, Bisht VK \& AK Bhandari (2013). Antidiarrheal activity of methanol extract and major essential oil contents of Saussurea lappa Clarke. Afr J Pharma pharmacol 7(8): 474-477.

5. Xiao PG (2006). Modern chinese materia medica. Beijing: Chemical Industry Press.

6. Backer WS, Aljefri AM \& Sawi AN (2012). Possible relief for migraine patients: Saussurea lappa. J US China Med Sci 9(1): 51-5.

7. Pandey MM, Rastogi S \& Rawat AKS (2007). Saussurea costus: botanical, chemical and pharmacological review of anayurvedic medicinal plant. $J$ Ethnopharmacol 110(3): 379-90.

8. Huntose Y, Pandey KK \& Dwivedi M (1999). Response of herbal drug (kustha) on Psychological and neurobehavior changes during labour. In: South-East Asian Seminar on Herbs and Herbal Medicines, Patna, India, January 16-19, pp 63-68.

9. Yuuya $\mathrm{S}$, Hagiwara $\mathrm{H} \&$ Suzuki $\mathrm{T}$ (1999). Guaianolides as immunomodulators, synthesisand biological activities of dehydrocostus lactone, mokko lactone, eremanthin, and their derivatives. J Nat Prod 62(84): 2230.

10. Jeong S, Itokawa T \& Shibuya M (2002). Costunolide, a sesquiterpene lactone from Saussurea lappa, inhibits the VEGFR KDR/Flk-1 signalling pathway. Cancer Lett 187(1/2): 129-133.

11. Malik MM \& Naqvi SHM (1984). Isolation and identification of an insect repellent compound from Saussurea 
lappa C. B. Clarke. Pak J Sci Ind Res 27(3): 144-145.

12. Liu ZL, Q. He Q \& Chu SS (2012). Essential oil composition and larvicidal activity of Saussurea lappa roots against the mosquito Aedes albopictus (Diptera: Culicidae). Parasitol Res 110(6): 212530.

13. Lirussi D, Li J \& Prieto JM (2004). Inhibition of Trypanosoma cruzi by plant extracts used in Chinese medicine. Fitoterapia 75(7/8): 718-23.

14. Julianti $\mathrm{T}$, Hata $\mathrm{Y}$ \& Zimmermann $\mathrm{S}$ (2011). Antitrypanosomal sesquiterpene lactones from Saussurea costus. Fitoterapia 82(7): 955-959.

15. Ohnishi M, Yoshimi N, Kawamori N, Ino N, Hirose Y \& Tanaka T (1997). Inhibitory effects of dietary protocatechuic acid and costunolide on 7, 12-dimethylbenz[a] anthraceneinduced hamster cheek pouch carcinogenesis. Jpn J Cancer Res 88: 111-9.

16. Gu JQ., Gills JJ, Park EJ, E. MataGreenwood, Hawthorne ME, Axelrod F, Chavez PI, H. H. Fong, R. G. Mehta, J. M. Pezzuto \& A. D. Kinghorn. (2002). Sesquiterpenoids from Tithonia diversifolia with potential cancer chemopreventive activity. $J$ Nat Prod 65(4): 532-536.

17. Yamahara J, Kobayashi M, Miki K, Kozuka M, Sawada T \& Fujimura H (1985). Cholagogic and antiulcer effect of Saussurea radix and its components. Chem Pharm Bull 33: 1285-1288.

18. Yoshikawa M, Hatakeyama S, Inoue Y \& Yamahara J (1993). Saussureamines A, B, C, D and E, new anti-ulcer principles from Chinese Saussurea radix. Chem Pharm Bull 41: 214-216.

19. Sutar N, Garai R, Sharma US, Singh N \& Roy SD (2011). Antiulcerogenic activity of Saussurea lappa root. Inter J Pharm Life Sci 2: 516-520.

20. Choi JY, E. H Choi EH, Jung HW, Oh JS, Lee WH, Lee JG, Son JK, Kim Y \&
Lee S H (2008). Melanogenesis inhibitory compounds from Saussureae Radix. Arch Pharm Res 31: 294-299.

21. Kuniyal CP, Rawat YS, Oinam SS, Kuniyal JC \& Vishvakarma SCR (2005). $S$. costus (Saussurea lappa) cultivation in the cold desert environment of the Lahaul valley, northwestern Himalaya, India: arising threats and need to revive socio-economic values". Biodiver Conserv 14: 1035-1045.

22. Nisa Z, Jan S \& Shah SH (2016). Standardization of Protocol for the Surface Sterilization and Callus Induction of Saussurea lappa: An Endangered Medicinal plant. Inter $J$ Biosci 9(1): 324-330.

23. Ahmad M, Nangyal H, Imran M \& Ullah F (2016). Optimization of Protocol for Surface Sterilization and Callus Induction for Three Rice Varieties AmEuras. J. Agri Env Sci 16: 357-361.

24. Rao SA, Kelkar GR \& Bhattacharya SC (1959). The structure of costunolide, a new sesquiterpene lactone from costus root oil. Tetrahedron Lett 9: 275-283.

25. Calixto JB (2000). Efficacy, Safety, Quality control, marketing and regulatory guidelines for herbal medicines. Braz J med Biol Res 179-189.

26. Lima MRF, Ximenes ECPA, Luana JS \& Sant Ana AEG (2006). The antibiotic activity of some Brazilian medicinal plants. Braz J Pharmacogn 16: 300-306.

27. Eliza J, P. Daisy $P$, Ignacimuthu $S$ \& Duraipandiyan V (2009). Normoglycemic and hypolipidemic effect of costunolide isolated from Costus speciosus (Koen ex. Retz.) Sm. In streptozotocin-induced diabetic rats. Chem Biol Interact 179: 329-334.

28. Eidi A \& Eidi M (2009). Antidiabetic effects of sage (Salvia officinalis L.) leaves in normal and streptozotocininduced diabetic rats. Diabetes and metabolic syndrome. Clin Res Rev 3: 4044. 